REVISTA DE LA UNIVERSIDAD DEL AZUAY

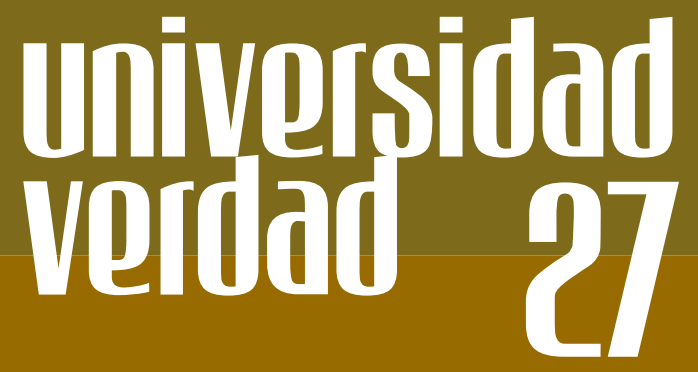

UNIVERSIDAD

DEL AZUAY

\title{
EL TÓTEM VIRTUAL
}

Andrés Abad Merchán

Director Cultural del Banco Central del Ecuador, Cuenca 


\section{La anécdota}

Inicia el semestre. Los alumnos entran a clase y toman asiento en sus puestos habituales. Es su primera clase, y da la casualidad que es de antropología cultural. Sus amigos, que ya han tomado la asignatura anteriormente, dicen que es interesante. Que en ella se habla de costumbres de pueblos y exóticos que todavía se los tilda como "primitivos". Que se estudia la cultura y las tradiciones. Que se habla de mitos y de leyendas. También de los enigmas fascinantes de la evolución. De piezas arqueológicas perdidas en el tiempo. De lenguajes, espíritus, demonios y dioses; de parentesco, familia y organización de los seres humanos entre sí; de arte. Y de símbolos.

De pronto, ingresa el profesor al aula colmada por los ávidos estudiantes, quienes están listos para desentrañar el misterio que han imaginado. El docente da la bienvenida, mira la lista y no falta nadie. Saca su cuaderno de notas y comienza la clase. Primero se confiesa; afirma que cada vez es un reto enseñar esta asignatura, pues en la actualidad la antropología se está transformando vertiginosamente, porque se interesa más en los estudios de las sociedades contemporáneas, y que, con el advenimiento de la era digital, es necesario incorporar el componente virtual. Habla de la ciberantropología y luego se refiere al contexto sociocultural en el que surgieron los principales estudios con carácter antropológico en la cultura clásica occidental.

El profesor se refiere a la riqueza legada por el mundo griego. Cita a Heródoto. Habla del Renacimiento y se detiene en Tomás Moro. Dice que Moro nació en 1479 en Londres, que perteneció a la generación de los grandes humanistas de su época y que vivió en la era de los gigantescos descubrimientos geográficos, es decir, en un período de transición hacia un "nuevo mundo", y que se puede partir 
de sus ideas para poder entender lo que se ha venido a llamar como la sociedad del conocimiento, que es una suerte de mundo imaginario similar a su "Utopía", que es el nombre de una isla imaginaria regida por leyes instauradas por el sabio Utopos, también imaginario. Dice que la organización social de esta isla aseguraba a todos sus habitantes el máximo de felicidad posible, pues sus principios posibilitaban la comunidad de los bienes, la tolerancia religiosa, la obligación impuesta a todos a trabajar seis horas diarias y el goce del ocio en actividades artísticas; en un sistema así, afirma en tono irónico, se supone la posibilidad de que el hombre alcance una organización donde ya no es necesario introducir ningún cambio. Anota ciertas analogías peligrosas.

$\mathrm{Y}$, concluye, que los profetas de la ciencia y la tecnología vaticinan el mejor de los mundos posibles una utopía que se acerca, si bien no se trata del fin de la historia, por lo menos se alcanza un punto de inflexión en su trayectoria. Pero advierte que la antropología, como crítica cultural, puede ser la herramienta que permita leer ese plan preestablecido por la "mano invisible" de la que una vez habló Adam Smith, ese filósofo y economista escocés, hace ya más de dos siglos, para, precisamente, romper con algunas ideas preestablecidas por las fuerzas construidas por la sociedad de consumo y poder entender mejor el "nuevo mundo virtual" que comienza a invadirnos como una época de los "modernos primitivos". El maestro saca un libro de su maletín y lee a Octavio Paz: "Menos natural y del todo injustificada ha sido la preeminencia del cientismo, una superstición moderna...". Termina la clase. Los alumnos, un poco confundidos frente a estas extrañas reflexiones, abandonan en silencio el aula.

\section{La Antropología en la tradición}

La anécdota, aunque parezca un poco fuera de lugar, advierte sobre la necesidad de la antropología, de pensarse a sí mismo y redireccionar muchos de sus intereses ante las nuevas realidades de la sociedad contemporánea, del nuevo orden mundial y del advenimiento de la tecnología digital con sus mundos virtuales. 
En la tradición del estudio de la antropología, como ciencia social, se parte del análisis de los llamados clásicos, que son las obras de Edward Taylor y Henry Morgan. A este último se lo considera el fundador de la antropología estadounidense, escribió su opus magnum en 1877 con el título de La Sociedad Primitiva. Influido con los conceptos evolucionistas de la época, Morgan sintetiza la evolución sociocultural de la humanidad en base a tres períodos étnicos: salvajismo, barbarie y civilización. En cada uno de estos ciclos se destaca un elemento tecnológico de la cultura que provoca la permanencia en dicho estado (Cfr. Juárez y Serdám, 1995: 53).

Taylor, por el contrario, conocido como el padre de la antropología británica, escribió su obra fundamental en 1871 con el nombre de Primitive Culture, en la que aparece el concepto de cultura más usado, toda vez que existen por lo menos, solo en el campo antropológico, doscientas definiciones. "Cultura, dice Taylor, es el conjunto complejo que incluye conocimientos, creencias, arte, moral, ley, costumbre y otras capacidades, y hábitos adquiridos por el hombre como miembro de la sociedad" (Ibidem: 55).

La antropología, entonces, estudia al ser humano como creador de cultura, preocupándose de su pasado remoto como referente para el análisis de sus circunstancias en el presente y posibilidades en el futuro. Se divide en dos grandes campos; uno que enfatiza el estudio de los elementos físicos que lo componen y otro, que es el que nos ocupa, estudia el comportamiento aprendido, es decir de su herencia social.

Una malévola pero útil definición de la antropología social y cultural es "el estudio del sentido común". Pero el sentido común está, antropológicamente hablando, mal llamado: no es ni común a todas las culturas ni ninguna de sus versiones es particularmente sensata desde la perspectiva de alguien ajeno a su contexto cultural particular". (Herzfeld: 1/25).

Ahora bien, el hecho de registrar datos de diversa índole, bien sea en las costumbres, técnicas, artes, ideología, religión, técnicas 
en general, no garantiza un trabajo de índole antropológico. Con la elaboración de categorías clasificatorias y, sobre todo, en la búsqueda de ciertas generalizaciones se pueden dar las primeras explicaciones científicas.

Ciertamente, los trabajos recientes han estado dedicados a estudiar las exigencias de la tecnología, de la política y aun de la ciencia. Esta disciplina ha visto la expansión del conjunto de sus temas y hasta hace poco se creía que "la principal misión de la antropología era el estudio de lo social con todos sus ámbitos -la política, la economía, el parentesco, la religión, la estética, etc.- en aquellas sociedades cuyos miembros no habían aprendido a hacer distinciones tan abstractas" (Ibidem: 2). A pesar de haber perdido vigencia el evolucionismo, se seguía hablando de sociedades "modernas" o "avanzadas" en contraposición a las "antiguas" o "atrasadas".

Muchos se preguntan si la antropología corre algún riesgo de desaparecer ante la inminente extinción de las microculturas tribales que eran su tradicional objeto de estudio. Si bien es cuestionable la tesis de una absoluta desaparición de estas culturas, no obstante cada vez más están asimiladas a las culturas mayoritarias, por lo que prácticamente en muy poco tiempo estarán completamente comunicadas con la sociedad global. Sin embargo, la antropología tiene sustento y vida propia. Con el tiempo ha reformulado sus objetivos, y ha abierto una multiplicidad de puertas en las que ha centrado su atención. Por ello, cada vez más se interesa de los problemas de la sociedad postindustrial y de la era digital, ello ha llevado a abrir ciertos senderos sobre temáticas contemporáneas.

Lo importante en todo caso, sea cual fuere el objeto de su estudio, tanto en una comunidad en la Amazonía como en uno de los barrios más populosos de Nueva York, es la determinación de su método, que es el comparativo transcultural, pues "estudiar lo que hacen 'otros' hombres es hoy más importante ya que esos 'otros' están más cerca y nos influyen más que en otras épocas" (Espina Barrio, 1996: 34). 
A pesar de que el desarrollo de los medios de comunicación ha llevado a pensar sobre cierta uniformidad cultural en el mundo, el ser humano con sus variantes culturales presenta todavía un enorme abanico de comportamientos que giran alrededor de una infinidad de temas que serán objeto de estudio del antropólogo. "La batalla entre la uniformidad y la diferencia no ha concluido y tiene visos de no concluir por mucho tiempo" (Ibidem: 35).

\section{La Ciberantropología}

La Ciberantropología se la define como el estudio del ser humano en las comunidades virtuales y en los ambientes de redes digitales. Entendida, entonces, la antropología como el estudio de la cultura en una comunidad dada, es preciso, para definir y entender el concepto de Ciberantropología, partir de la reflexión y alcance de la cultura en un mundo virtual. Lo primero es reconocer que las comunidades no son sólo aspectos geográficos ni exclusivamente semióticos -bien sea desde la perspectiva étnica, religiosa o lingüística- de lo contrario no se podría incursionar en el uso de prefijo "ciber", que, como la "Utopía" de Moro, no deja de ser un interesante lugar "imaginario". Por el contrario, una comunidad en el sentido virtual es construida en el llamado ciberespacio sobre la base de un "interés común de afiliación", en el que trascienden las barreras de clase, religión, raza, nación, género y lenguaje (Cfr. www.clas.ufl.edu/anthro/Cyberanthro).

Cuando se navega por la Internet se incursiona en las comunidades y chats, en donde se percibe precisamente la construcción de un "nuevo mundo" en el que el proceso de interactividad no reclama ningún componente cultural o geográfico clásico, sino se funda en la unidad de intereses. Si se crea una comunidad en uno de los lugares en los que se lo puede hacer, bien sea en Hotmail, AOL, Yahoo o Altavista, la base de dicha creación se funda en la necesidad de un "común interés de afiliación", verbigracia: cine clásico, arte digital, automóviles de competencia, astronomía hindú, literatura francesa, arqueología andina, música celta, clonación de seres humanos, rosacrucianismo, tarot, etc. 
En otras palabras, cualquier área del humano saber, ser y hacer, puede convertirse en un "interés afiliativo" con el objeto de constituir una comunidad en el ciberespacio, por lo que el aspecto racial, por ejemplo, pasa a un segundo plano. Lo que es inevitable para que se establezca una comunicación eficiente es el uso de una lengua común, y este componente es fundamental en la concepción clásica de la antropología, pues se necesita del uso de un código para participar de la experiencia conjunta. Es por ello que, las comunidades, desde la estricta perspectiva de lo cultura, se dividen en comunidades en inglés, español, alemán, francés, y luego en el área específica de interés.

La Ciberantropología se fundamenta también en la lógica que si una comunidad en el sentido antropológico es factible de ser estudiada con categorías de las ciencias sociales, las comunidades virtuales pueden entonces, ser entendidas también bajo conceptos similares. Es decir, en las comunidades virtuales seguramente se crean necesidades de comunicación, organización, supervivencia, cooperación, filiación y aún de parentesco. Es obvio que para el "etnógrafo virtual", que será la persona dedicada en levantar la información descriptiva, se presenta un verdadero reto, pues tiene que lidiar con una categoría amplia de seres humanos que en algún momento incluirá la inteligencia artificial y a los androides.

Uno de los principios de la antropología radica en que, lo que convierte a los seres humanos en tales, se fundamenta en la habilidad de intercambiar información simbólica entre sus semejantes, también en la capacidad de transmitir conocimiento y experiencia de una generación a la siguiente, lo que las redes neuronales estarán muy pronto de lograr (Cfr. Ibidem). Por lo tanto, algún día las máquinas estarán en capacidad de jugar al etnógrafo una mala pasada.

La Ciberantropología, gracias a que posee un canal binario de transmisión de la cultura, mira al ser humano como un transmisor dígito-análogo de información , pero no en el sentido comparativo al que el filósofo LeMettrie se refería, pues en la época de la llustración 
-por la influencia de la Revolución Industrial- el símil del ser humano era una máquina humeante y contaminante, al vapor. En esta época digital post-MacLuhan consideramos que el ser humano no es solamente un procesador de combustible (comida) en energía (trabajo). "Ellos también absorben y transmiten unidades de información o memes. Si los genes son el código del cuerpo físico del ser humano, entonces debemos pensar en los memes como la programación de la biocomputadora que llamamos cerebro" (Ibidem: p. 2).

La analogía descrita podría estar mucho más en el terreno de la ficción, sin embargo, con el advenimiento de las computadoras en la vida cotidiana se está tratando con una realidad cada vez más cercana, lo que ha provocado un renacer en el estudio de la conciencia volviendo de moda categorías psicosociales, que estaban en letargo, tales como epistemología, identidad, y teoría del conocimiento en general.

Para la antropología, especialmente en las teorías ligadas a la ecología cultural que miran al ser humano en una permanente adaptación al entorno, son importantes los grandes hitos que han acelerado su proceso evolutivo, llámese capacidad de simbolizar (que lo hizo saltar de la animalidad a la humanidad"; uso de las manos, de la piedra, del fuego, la invención de la rueda, la revolución neolítica (agrícola), industrial, etc. Estos hitos tienen un enorme impacto en los factores intrínsecos de la cultura, como por ejemplo, organización social o cosmovisión para citar solamente dos.

Para la Ciberantropología estamos actualmente en un punto de inflexión en la historia humana, un ápex, similar a la revolución neolítica hace diez mil años, o aun más atrás, a una época comparable al momento en que se produjo el salto cualitativo en los antiguos antropoides, hace más de cuatro millones de años, quienes, gracias a la capacidad de manipular símbolos (la primera herramienta humana), se convirtieron en seres erguidos que aprendieron a caminar solo en dos patas.

Por tal razón, estamos en una nueva etapa para que se produzca 
un "salto" en la especie, por lo que podríamos ser calificados como "modernos primitivos", denominación que usarán seguramente las generaciones futuras, dentro de miles de años. Esta época de "modernos primitivos", según Steve Mizrach, creador del Web-site sobre CyberAnthropology (web. cit. Supra, de donde hemos obtenido abundante información sobre el tema) dice que en esta era posmoderna se produce una acelerada colisión entre el pasado y el futuro. Mizrach afirma que una subdisciplina de la llamada ciberantropología es el antropo-futurismo, que se dedica a conocer el impacto antropológico y la alta tecnología.

La antropología clásica, de Morgan y Taylor, estaba más concentrada en el pasado que en el futuro. Estos dos evolucionistas de la cultura llamaron a los pueblos estudiados como "salvajes" o "primitivos", porque asumieron que eran remanentes de una antigua época de la humanidad, por supuesto acogiendo un término que, a todas luces, es etnocentrista. Incluso, después de la segunda guerra mundial los pueblos "primitivos" o llamados también "pre-modernos" siguieron siendo estudiados por los antropólogos con la suposición que la modernidad y la civilización de Occidente los iba a absorber. ¿Pero qué sucede ahora? Mizrach en su artículo "What is AnthroFuturism?" dice:

Hoy en día, evidentemente, este viejo sistema de evolucionismo ha empezado a declinar del discurso antropológico (a pesar que el darwinismo cultural sociobiologicista ha regresado)... En efecto el contacto cultural y la difusión es un camino de doble vía. Lo moderno ha acogido lo primitivo ('gone native") así como lo primitivo se ha modernizado. Los antropólogos están porlo menos estudiando a plenitud la gente aquí en el presente, incluyendo sociedades high-tech "avanzadas", sin la suposición ingenua sobre un cambio evolutivo lineal y continuo (Web cit. p. 1).

En el camino del antropo-futurismo Donna Haraway habla de la "cyborg anthropology" (los cyborg es un ser mitad humano, mitad máquina), debido a que la tecnología está invadiendo el cuerpo 
humano de una manera inevitable, a través de los implantes, prótesis, órganos artificiales, cirugía plástica, trasplantes, etc., lo que nos está convirtiendo, de alguna manera a todos en cyborgs, pues el concepto básico es la sustitución de lo que nos dio la naturaleza con un elemento tecnológico. Aquí la paradoja estructural se pone en evidencia, pues aparece la dicotomía naturaleza vs. cultura, como lo crudo y lo cocido, que habla el antropólogo Claude Lévi-Strauss. Aquí se deja en el tapete uno de los dilemas básicos de la humanidad de siempre.

\section{Tótem punto com.}

Con la definición de la Ciberantropología, es preciso hacer un ejercicio de imaginación. La premisa que se refiere a que las comunidades reales y las virtuales tienen comportamientos análogos es la puerta de entrada al análisis. Y es factible que haya la necesidad de los tótemes en el mundo virtual, o, por lo menos, que la colectividad haya creado su necesidad. El tótem fue un elemento sustancial en las sociedades "primitivas", y aun, en forma simbólica, lo es en la nuestra. Adicionalmente, bajo la perspectiva de que estamos en el ápice de una nueva historia de "modernos primitivos", la necesidad de elementos simbólicos de la cultura permite hablar de la exigencia de referentes culturales en el complejo mundo del ciberespacio.

En suma, para los habitantes de una comunidad virtual, debe existir el deseo inconsciente de buscar un ancestro común como referente de filiación. Al menos esta es la hipótesis de trabajo.

\section{Y partimos al análisis con ésta.}

La definición general de tótem dada por Sigmund Freud dice que es un "animal comestible, ora inofensivo, ora peligroso y temido, y más raramente una planta o una fuerza natural (lluvia, agua) que se hallan en una relación particular con la totalidad del grupo" (Enciclopedia Encarta, 2000). La palabra en sí, es originaria de los indios ojibwa de América del Norte, cuyo significado se asocia al de 
"guardián personal", protector o guía de una persona, y por lo tanto existe una relación de parentesco aparente con el tótem, con todos los derechos y obligaciones que ello amerita. "La sociedad ojibwa se dividía en cinco clanes principales, los cuales a su vez se subdividían en grupos menores que llevaban el nombre de algún animal o tótem. Los cinco grandes clanes y sus subgrupos eran los siguientes: pez, grulla, somorgujo, oso, alce" (Wiseman y Groves, 1999: 39).

El totemismo es un sistema social fundado en aspectos ideológicos para establecer relaciones intrínsecas y extrínsecas del clan en referencia. Por lo tanto, no representa por sí mismo una forma de religión o algo similar. El tótem, de hecho, tiene funciones distintas en las culturas, cuyos miembros llegan a tener una especie de relación mística con él. Si se asume un animal como tótem, este no puede ser sacrificado ni consumido, puesto que es el guardián o protector del grupo. El elemento totémico se convierte en el emblema o insignia hereditarios del grupo que recibe su nombre.

Claude Lévi-Strauss propuso que no existía entre el individuo y su clan totémico ninguna relación de tipo "místico", como proponían sus predecesores en el estudio de esta temática. Para él es como un código que sirve como instrumento para clasificar los grupos sociales. "Las diferencias entre un clan A y un clan B son las mismas que existen entre el jaguar y el oso. Esto puede traducirse, verbigracia, diciendo: ambos son clanes de cazadores, pero no rivalizan entre sí". Así se codifican las diferencias en la sociedad, análogas a las observadas en el mundo natural (Ibidem: 46, 47).

El animal totémico es por definición un sistema global proclive a subdividirse en partes y, a su vez, éste es parte de una especie, dando una secuencia de la forma: especie - animal totémico - partes del cuerpo. Esto se conoce como el operador totémico. Y las personas que forman parte de cada subdivisión conocen el lugar exacto en el que se encuentran dentro de una organización social.

Uno de los objetivos básicos de la antropología desarrollada por Claude Lévi-Strauss fue el de demostrar que las "operaciones 
mentales fundamentales" que animaban el pensamiento en todo el mundo eran las mismas, por ello llegó a decir: "L'homme a toujours pensé aussi bien" (el hombre siempre pensó tan bien como ahora). Es obvio que las circunstancias en las que aplicó ese pensamiento fueron en extremo diversas (Cfr. Ibidem).

En síntesis, el tótem es un animal, planta o fuerza natural, frente al cual un grupo social se siente vinculado, como símbolo de unión. Y destacamos fuerza natural, pues será este el referente para buscar, por analogía, un referente simbólico clasificatorio en las comunidades virtuales dentro del ciberespacio.

Al ingresar en las páginas virtuales de los buscadores, como Hotmail o Yahoo, se ve que mantienen espacios para chats y comunidades virtuales, y la referencia de quien ingresa a esas páginas se convierte en la página principal, allí es donde radica la fuerza natural de la que hablamos, o por lo menos es lo más cercano a ello, es el referente de filiación. Detrás de las máquinas hay un componente puramente humano, sensible y solidario que interactúa con sus congéneres, estableciendo relaciones de carácter social y antropológico.

Pero la necesidad de filiación y organización aparece, a pesar de la volatilidad de los medios, por lo que la hipótesis de la existencia de un tótem virtual se vuelve una idea plausible. Pero en la medida que se va ingresando en las diversas categorías de clasificación -ya que de clasificación están compuestas las redes de parentesco- se va acercando uno a la comunidad elegida. La búsqueda por parte de lo general a lo particular, ejemplo: de la página principal del Hotmail se accede luego a los chats, de ahí a la temática preferida, por decir religión, y de ahí se crea una comunidad con la temática, por decir, de ángeles. En esta comunidad hipotética de personas, aparentemente anónimas y distantes, que discuten y conversan sobre ángeles, se va creando con el tiempo una necesidad de filiación, producto de una amistad creada en lo virtual, que poco a poco se va integrando.

Los elementos de parentesco y de referente simbólico para todos 
los que forman parte de una comunidad virtual son varios, en primer lugar está el elemento simbólico de unión, que es "el común interés" y luego, como la resolución de un árbol de problemas se va ascendiendo al tronco común que es la página web principal, que ha sido de completa elección al inicio. En una visión estructural la referencia del ejemplo anterior se convierte entonces en la secuencia: hotmail - chats - religión - ángeles.

Esta secuencia, que el participante conoce de antemano, es una especie de operador totémico, que establece una forma de clasificar el lugar específico que ocupa una persona en el ciberespacio. Son como ramas que terminan en un tronco, para hablar en términos botánicos. Es decir, esta secuencia es la que convierte a la persona en un ser "real", en el mundo virtual.

La secuencia de lo simple a lo complejo, o de mayor a menor, como algoritmo matemático es la fuerza natural, el tótem virtual, análogo a lo que requiere el tótem para operar en el mundo real, y representa el ancestro simbólico clasificatorio que necesitan los habitantes de las comunidades virtuales, y que llevan en sus nombres registrado en el e-mail, como dominio después del símbolo @, que es como un apellido que sustenta la pertenencia a un gran conglomerado de habitantes en la red, por ejemplo: nombre@hotmail.com. De esta manera se está identificando la persona como miembro del clan A, que se diferencia del clan B.

Y así podremos afirmar como lo hizo Lévi-Strauss: “L’homme a toujours pensé aussi bien". No importa el tiempo ni el lugar. 


\section{BIBLIOGRAFÍA}

ESPINA BARRIO, Ángel, 1996, Manual de Antropología Cultural, Quito, Ediciones Abya-Yala.

HARRIS, Marvin, 1979, EI Desarrollo de la Teoría Antropológica, México, Siglo Veintiuno Editores.

HERZAFELD, Michael, "La Angropología: práctica de una teoría", en www.unesco.org./issj/rics153/herzfeldspa.html.

JUÁREZ, Roberto y SERDÁM, Héctor, 1995, Introducción a la Antropología 1, México, McGraw-Hill.

MIZRACH, Steve, "CyberAnthropology", "Anthrofuturism", "Modern Primitives", en xxx.clas.ufl.edu/anthro/cyberanthro/CyberAnthropology.html.

WISEMAN, Boris y GROVES, Judy, 1998, Lévi-Strauss para principiantes, Buenos Aires, Era Naciente SRL. 
